\title{
COMPARATIVE ANALYSIS OF LAND SURFACE TEMPERATURE AND LAND COVER BASED ON GEOGRAPHICALLY WEIGHTED REGRESSION
}

\author{
XU, D. - GAO, J.* \\ Shanghai Normal University, School of Environmental and Geographical Sciences \\ Shanghai 200234, China \\ Corresponding author \\ e-mail: gaojunshnu@126.com \\ (Received 12 $2^{\text {th }}$ Jun 2019; accepted $12^{\text {th }}$ Jul 2019)
}

\begin{abstract}
The relationship between land surface temperature (LST) and land use patterns has long been explored to understand the impact of urbanization on the urban heat island effect. This paper reports the geographically weighted regression method. The LST is derived from the radiation transfer model and the urban reflectance is grouped into three types from the linear spectral mixture in Nanjing City, China. The high LST on October 3, 2009 in the central city, suburbs, outer suburbs, and outer suburbs near water were $44,40,36$, and $33^{\circ} \mathrm{C}$, respectively. The LSTs of the central city in spring, summer, and autumn were $1-5^{\circ} \mathrm{C}$ higher than that of the suburbs. The high absorption coefficient of vegetation, substrate, and dark surfaces with LST were $-0.80,1.05$, and -1.64 , respectively. The promoting role of impervious surfaces is much higher than the cooling effects of vegetation on LST. Water surfaces have a more obvious effect on adjusting LST. If the landscape diversity index or the fragment index are low, the vegetation cover has a more noticeable negative correlation with LST. The way in which LST relates to land reflectance and to landscape provides a quantitative reference for urban planning of sustainable development in Nanjing.

Keywords: spectral unmix, heat island, landscape indices, Nanjing, radiative transfer equation
\end{abstract}

\section{Introduction}

The main feature of the urban heat island effect is that the LST in central urban areas is higher than that in the suburbs (Landsberg, 1831). In the study of the urban heat island pattern, remote sensing data for land surface temperature (LST) inversion were mainly gathered by the National Oceanic and Atmospheric Administration's Advanced Very-High-Resolution Radiometer (AVHRR), Moderate Resolution Imaging Spectroradiometer (MODIS), Landsat Thematic Mapper/Enhanced Thematic Mapper (Landsat TM/ETM), and Advanced Spaceborne Thermal Emission and Reflection Radiometer (ASTER). The urban area is firstly determined using the temperature difference between the urban and rural surface detected by AVHRR (Rao et al., 1972). Heat island intensities from AVHRR data are highest in the day time and in the warm season for towns in North America (Roth et al., 1989). Qin et al. (2001 a,b) proposed a single window algorithm for Landsat TM/ETM and modified the land temperature inversion algorithm for MODIS. ASTER data is optimized using a neural network algorithm (Mao et al., 2008). A split window algorithm is provided for Landsat 8 and the root mean square is determined as $0.93^{\circ} \mathrm{C}$ (Rozenstein et al., 2014). When the urban reflectance is known, the algorithms are divided into three types; the single-channel method (Coll et al., 2012), the multi-channel method (Atitar and Sobrino, 2009), and the multi-angle method (Sobrino and Jiménez-Muñoz, 2005). When the urban reflectance is not known, the algorithms are again divided into three types, but which differ from the preceding case; the stepwise retrieval method (Sobrino et al., 2008), simultaneous 
retrieval (Hulley and Hook, 2011), and simultaneous retrieval with unknown atmospheric information (Wang et al., 2013).

In a related analysis of the spatiotemporal characteristics of LST, the urban heat island magnitude is considered to be inversely correlated with the rural temperature (Streutker, 2002). The intensity of the urban heat island reached a maximum during the summer and a minimum during the winter periods. The overall relationship between urban heat island and population density have been quantitatively explored ( $\mathrm{Li}$ et al., 2012). The minimum temperature difference formed at the end of the cooling process increases with urban length and while wind speed is on the decline (Lee et al., 2012). The LST has been increasing in recent years, with an increase of LST in both rural and urban areas (Rajasekar and Weng, 2009; Alavipanah et al., 2015; Fu and Weng, 2016a; Haashemi et al., 2016).

By predicting the urban expansion pattern of cities in the Pearl River Delta of China and considering the LST and urban reflectance patterns, the radiation temperature is expected to increase by $13.01 \mathrm{~K}$ (Weng, 2001). LST possesses a more negative relation with the unmixed vegetation abundance than with the normalized difference vegetation index (NDVI) across the spatial resolution from $30 \mathrm{~m}$ to $960 \mathrm{~m}$ (Weng et al., 2004). The NDVI can be easily influenced by leaf area, view angle, and soil background, thus, it is not a suitable indicator for quantitative vegetation research (Small, 2001). The three-end members of substrate, vegetation, and dark surface, can represent more than $95 \%$ of the 30 million ETM+ image spectra with misfits of less than 0.04 (Small, 2004, 2005). There is a negative relation between LST and vegetation abundance, and a positive relation between LST and impervious surface. The rates of change of low and high temperatures differ depending on the impervious surface abundance (Small and Lu, 2006). The heat island effect is more noticeable in industrial and commercial areas (Zhang et al., 2012). The LST is expected to increase by $2.63^{\circ} \mathrm{C}$ by overall regression, and $3.17^{\circ} \mathrm{C}$ from geographically weighted regression, and additionally, according to an analysis of the accuracy the overall regression underestimates the heat island effect and its risks (Su et al., 2012). High-intensity urban land in Atlanta has the highest mean LST value of $294.9 \mathrm{~K}$ with a yearly amplitude of $17.4 \mathrm{~K}$ (Fu and Weng, 2016b). Information support systems for urban heat landscape have been proposed to simulate the urban heat island and mitigate these effects (Quattrochi et al., 2000). Landscape indices can also be used to predict the LST. The landscape dominance index and the landscape shape index account for $56 \%$ and $6-12 \%$ of the variance of the LST, respectively (Chen et al., 2014).

In spite of these significant studies, there are few studies of the regional arithmetical relation between LST and urban reflectance. Using Landsat TM/ETM imagery of Nanjing City, this study aims to illustrate the quantitative relation between LST and urban reflectance Specific objectives of this study are as follows: (1) to derive the LST and analyze its temporal, spatial, and fractal characteristics. (2) to apply linear spectral unmixing to analyze the urban reflectance of vegetation, substrate, and dark areas. (3) to investigate the relation between LST and vegetation, substrate and dark abundance using geographically weighted regression (GWR). This research also investigates the relation between LST and the enhanced vegetation index (EVI) under landscape diversity indices and fragment indices. 


\section{Materials and Methods}

\section{Study Sites}

Nanjing City is in the central region of the Yangtze river downstream at $118^{\circ} 22^{\prime}-119^{\circ} 14^{\prime} \mathrm{E}, 31^{\circ} 14^{\prime}-32^{\circ} 37^{\prime} \mathrm{N}$ in Jiangsu province. The total area of Nanjing City was $6597 \mathrm{~km}^{2}$, with $1427.81 \mathrm{~km}^{2}$ of built area in 2018. Nanjing City has a humid subtropical climate. The average, maximum (summer), and minimum (winter) temperatures, are $15.4,39.7$, and $-13.1^{\circ} \mathrm{C}$, respectively. Rainfall averages $1006 \mathrm{~mm}$ per annum. Nanjing's geomorphology is primarily characterized by low mountains and low hillocks, with 3.5\% low mountains, $4.3 \%$ hilly areas, 53\% low hillocks, and $39.2 \%$ plains and rivers ( $\mathrm{Li}$ et al., 2016). The natural vegetation is mixed deciduous forest and broadleaf evergreen forest. Nanjing includes seven districts, Central, Jiangning, Qixia, Pukou, Liuhe, Lishui, and Gaochun districts, respectively (Fig. 1).

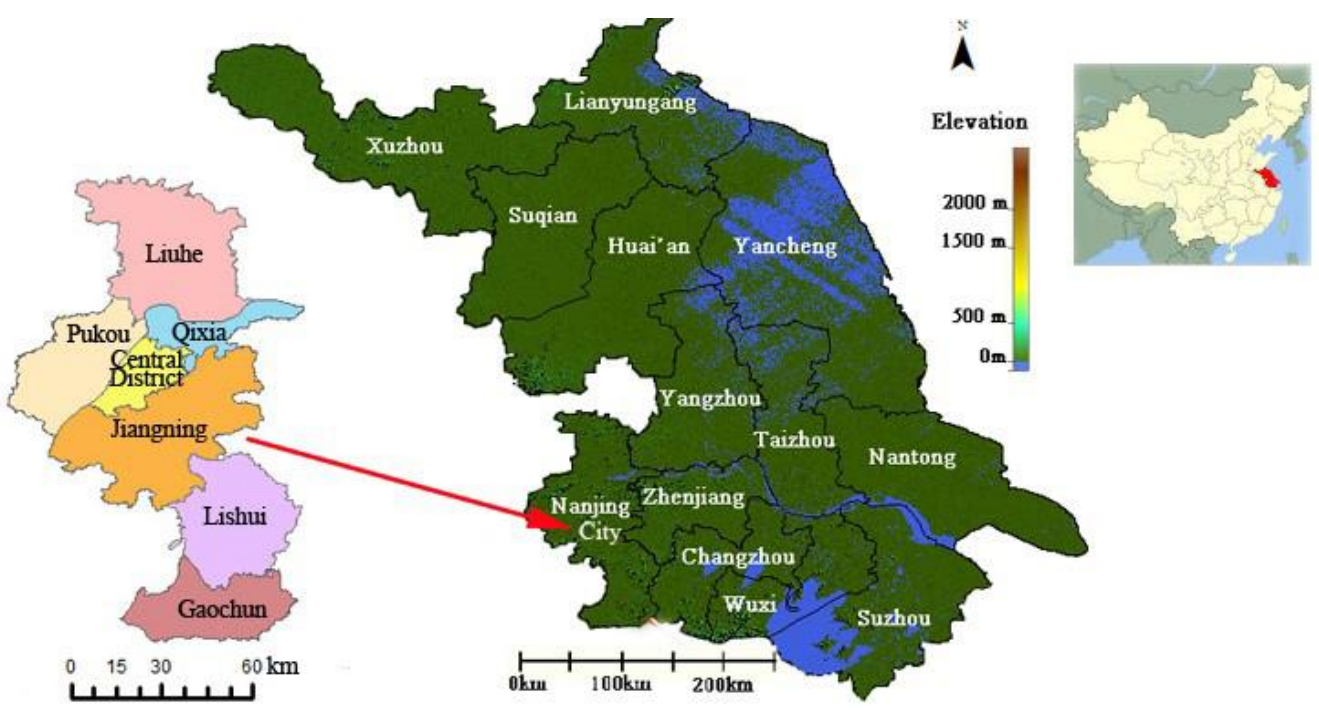

Figure 1. Nanjing City of China. There are seven districts in Nanjing.

Nanjing is the Capital of Jiangsu province with nearly 2000 years of history. The GDP of Nanjing was 972.08 billion yuan in 2015, ranking $11^{\text {th }}$ in China. In 2015 Nanjing's industrial infrastructure account for $2.4 \%$ in primary industry, $40.3 \%$ in secondary industry, and $57.3 \%$ in tertiary industry. Nanjing's resident population in 2015 was 8.24 million and the urbanization rate was $81.4 \%$. The reform and open policy of the 1980s produced a rapid urbanization phase and further encroachment on the countryside. The Nanjing Plan of 1991-2010 proposed new towns around the main old city (Jim and Chen, 2003).

\section{Data}

The data sets were downloaded from the United States Geological Survey (USGS) website (http://glovis.usgs.gov/ accessed 7th March 2019). 22 Landsat images are used to derive the LSTs in Nanjing (Table 1). The Landsat TM image obtained on May 20, 2006 is utilized to derive the landscape diversity indices and fragment indices. The Landsat image obtained on October 3, 2009 is utilized to derive the fractions of substrate, vegetation, and dark surface land cover by linear spectral unmixing. 
Table 1. Dataset of Landsat images used without cloud or less than 5\% cloud

\begin{tabular}{c|c}
\hline Data set & Date \\
\hline LandSat TM 5 & $04 / 17 / 2000$ \\
LandSat TM 5 & $10 / 10 / 2000$ \\
LandSat TM 5 & $0 \mathrm{~d} 4 / 04 / 2001$ \\
LandSat ETM 7 & $07 / 17 / 2001$ \\
LandSat ETM 7 & $02 / 10 / 2002$ \\
LandSat TM 5 & $07 / 12 / 2002$ \\
LandSat TM 5 & $09 / 30 / 2002$ \\
LandSat ETM 7 & $10 / 24 / 2002$ \\
LandSat ETM 7 & $11 / 09 / 2002$ \\
LandSat ETM 7 & $12 / 27 / 2002$ \\
LandSat ETM 7 & $01 / 28 / 2003$ \\
LandSat TM 5 & $02 / 08 / 2004$ \\
LandSat TM 5 & $11 / 22 / 2004$ \\
LandSat TM 5 & $12 / 08 / 2004$ \\
LandSat TM 5 & $04 / 02 / 2006$ \\
LandSat TM 5 & $05 / 20 / 2006$ \\
LandSat TM 5 & $03 / 20 / 2007$ \\
LandSat TM 5 & $05 / 07 / 2007$ \\
LandSat TM 5 & $10 / 03 / 2009$ \\
LandSat TM 5 & $08 / 19 / 2010$ \\
LandSat TIRS 8 & $08 / 11 / 2013$ \\
LandSat TIRS 8 & $10 / 14 / 2013$ \\
\hline
\end{tabular}

\section{Methods}

\section{Radiative transfer equation}

The LST is obtained using the radiative transfer equation from the following expression (Berk et al., 1987; Sobrino et al., 2004).

$$
\mathrm{L}_{\text {sensor }}=\left(\varepsilon \mathrm{L}_{\lambda}+(1-\varepsilon) \mathrm{L}_{\uparrow}\right) \tau+\mathrm{L}_{\uparrow}
$$

where $L_{\text {sensor }}$ is the at-sensor radiance above the atmospheric radiance, $\varepsilon$ is the urban relectance, $\tau$ is the total atmospheric transmissivity between the land surface and the sensor, $\mathrm{L}_{\rrbracket}$ and $\mathrm{L}_{\uparrow}$ are the downwelling and upwelling atmospheric radiances, $\mathrm{L}_{\uparrow}$ and $\mathrm{L}_{\lambda}$

is the blackbody radiance given by Planck's law.

The formula for the actual temperature, $\mathrm{T}$ is as follows:

$$
\mathrm{T}=\frac{\mathrm{K}_{2}}{\operatorname{Ln}\left(\mathrm{K}_{1} / \mathrm{L}_{\mathrm{X}}+1\right)}
$$

where $\mathrm{K}_{1}$ and $\mathrm{K}_{2}$ are constants. For Landsat TM, K1 $=607.66$ and $\mathrm{K} 2=1260.56$, and for Landsat ETM, K1 = 666.09 and $\mathrm{K} 2=1282.71$.

$$
\mathrm{NDVI}=(\mathrm{TM} 4-\mathrm{TM} 3) /(\mathrm{TM} 4+\mathrm{TM} 3)
$$

where TM4 and TM3 are the near the infrared and red bands, respectively.

$$
\begin{aligned}
& \mathrm{F}_{\mathrm{V}}=\left[\left(\mathrm{NDVI}-\mathrm{NDVI}_{\mathrm{S}}\right) /\left(\mathrm{NDVI}_{\mathrm{V}}-\mathrm{NDVI}_{\mathrm{S}}\right)\right] \\
& \text { esurface }=0.9625+0.0614 \mathrm{~F}_{\mathrm{V}}-0.046 \mathrm{~F}_{\mathrm{V}}^{2}
\end{aligned}
$$




$$
\text { sbuilt }=0.9589+0.086 \mathrm{~F}_{\mathrm{V}}-0.0671 \mathrm{~F}_{\mathrm{V}}^{2}
$$

where $F_{\mathrm{V}}$ is the percentage of vegetation cover, and ssurface and sbuilt represent the emissivities corresponding to the natural and urban surfaces, respectively.

\section{Linear spectral mixture model}

The linear spectral mixture model assumes that the spectral reflectance of the field of view of a sensor can be expressed as a linear combination of the constituent end members (Small and Lu, 2006).

$$
R(\lambda)=f_{1} E_{1}(\lambda)+f_{2} E_{2}(\lambda)+\cdots+f_{n} E_{n}(\lambda)
$$

where $R(\lambda)$ is the observed reflectance, $\lambda$ is the wavelength, $E_{i}(\lambda)$ is the spectrum of the end members, $\mathrm{f}_{\mathrm{i}}$ is a coefficient representing the abundance of the corresponding end members.

The linear spectral mixture has two significant problems. One is to determine the number of end members related to surface reflectance. Another one is to determine the reflectance spectrum of end members. Linear spectral mixture models can be standardized by using end members that span the global mixing space. The mean substrate, vegetation, and dark end members can be used to define a global standard mixture model for Landsat spectra (Clement et al., 2009; Small and Milesi, 2013).

\section{Geographically weighted regression}

Geographic weighted regression is an extension of the traditional global regression because it allows for local regression rather than global parameter estimation (Fotheringham et al., 2001). The GWR method is also applied to LST and environmental driving factors (Buyantuyev and Wu, 2010; Zhou and Wang, 2011; Schwarz et al., 2012; Du et al., 2016).

The equation for the GWS model is:

$$
\mathrm{y}_{\mathrm{i}}=\beta_{0}\left(\mathrm{u}_{\mathrm{i}}, \mathrm{v}_{\mathrm{i}}\right)+\sum_{\mathrm{k}} \beta_{\mathrm{k}}\left(\mathrm{u}_{\mathrm{i}} \mathrm{v}_{\mathrm{i}}\right) \mathrm{x}_{\mathrm{ik}}+\varepsilon_{\mathrm{i}}
$$

where $\left(\mathrm{u}_{\mathrm{i}}, \mathrm{v}_{\mathrm{i}}\right)$ is the coordinate of the $i$-th point, $\beta_{\mathrm{k}}\left(\mathrm{u}_{\mathrm{i}} \mathrm{v}_{\mathrm{i}}\right)$ is the $k$-th regression parameter of the $i$-th point, and $\varepsilon_{\mathrm{i}}$ is the random error of the $i$-th sample.

Data near the $i$-th point will have a more profound effect on $\beta_{\mathrm{k}}\left(\mathrm{u}_{\mathrm{i}} \mathrm{v}_{\mathrm{i}}\right)$ than data further away.

$$
\hat{\beta}(u, v)=\left(X^{T} W(u, v) X\right)^{-1} X^{T} W(u, v) y
$$


where $\widehat{\beta}(\mathrm{u}, \mathrm{v})$ represents the unbiased estimate of $\beta, w\left(u_{v}, v\right)$ is a weight function, which ensures that observation points close to the specific point will have a large weight.

$$
W_{i j}=\exp \left(\frac{d_{i j}^{a}}{b^{2}}\right)
$$

where $W_{\mathrm{ij}}$ is the weight of observation point $j$ related to the point $i$.

If the observation point $j$ coincides with point $i$, the weight of point $j$ is 1 . If the distance between points $j$ and $i$ is greater than the bandwidth, the weight of point $j$ is zero. Thus, the GWR model takes the bandwidth into account.

\section{Landscape indices}

The land surface is classified into five types by an un-supervised classification method and checked with Google Earth, including farmland, forest, water areas, construction land and other land. Based on the land classification, landscape diversity and Landscape fragmentation indices are calculated by fragstas.

\section{Results}

\section{The Character of Urban Reflectance and LST}

The urban reflectance is classified into three types by linear spectral unmixing, including the substrate fraction (Fig. 2a), vegetation fraction (Fig. 2b), and dark fraction (Fig. 2c). The LST is inversed by radiation transfer model in Nanjing City on October 3, 2009.
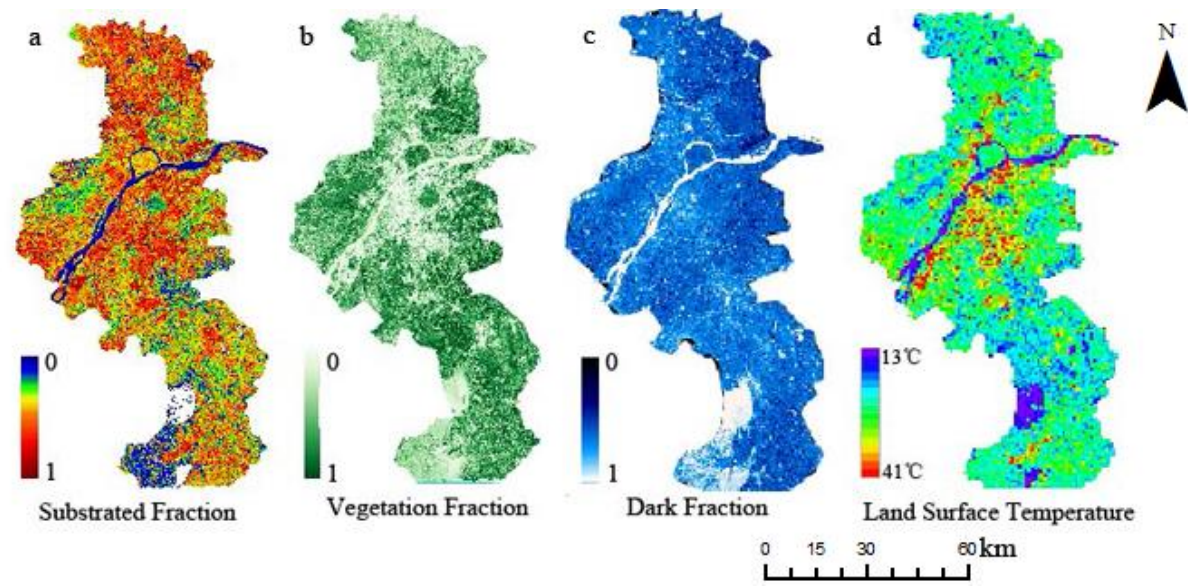

Figure 2. The urban reflectance and LST in Nanjing City on October 3, 2009. The fraction of impervious surface from 0-100\% (Fig.2a). Vegetation fraction (Fig.2b). Water Fraction

(Fig.2c). LST (Fig.2d)

High impervious surface fractions are mainly distributed in the middle and the north part of Nanjing City (Fig. 2a). The central city of Nanjing is in the center along the Changjiang river. With urbanization, the impervious surface is gradually extending in 
the northerly direction. Low vegetation surface fractions are in the center of Nanjing City and some is also observed in the north (Fig. 2b). The vegetation in cultivated areas, forest parks, and undeveloped remote areas in the outer suburbs is less disturbed. High water surface fractions are in the middle and in the south, and correspond to the Yangtze river and Gucheng lake, respectively (Fig. 2c). Nanjing City with the high LST observed on October 3, 2009 is in the center of Nanjing (Fig. 2d). The high temperature area is larger than the area of the high impervious surface fraction. With the rapid progress of urban construction in Nanjing, the city is subject to a large number of anthropogenic heat sources, including fuel combustion, automobile exhaust, and air conditioning, increasing the air temperature. The development of commercial and service industries in Nanjing has resulted in business areas with dense population. These areas are have high densities so the heat is not easy to diffuse.

\section{Characteristics of the spatial dimension of LST}

Taking the city of Nanjing as the center, and extending to the north, east, south, and west we make a temperature profile for October 3, 2009 (Fig. 3). The LST profile serves to observe the general characteristics of LST and horizontal distribution trends. The section of the profile running from north to central urban (Fig. 3a), has a low temperature of approximately $24^{\circ} \mathrm{C}$, corresponding to the Yangtze River basin, and the profile continues from central urban to the south (Fig. 3b).

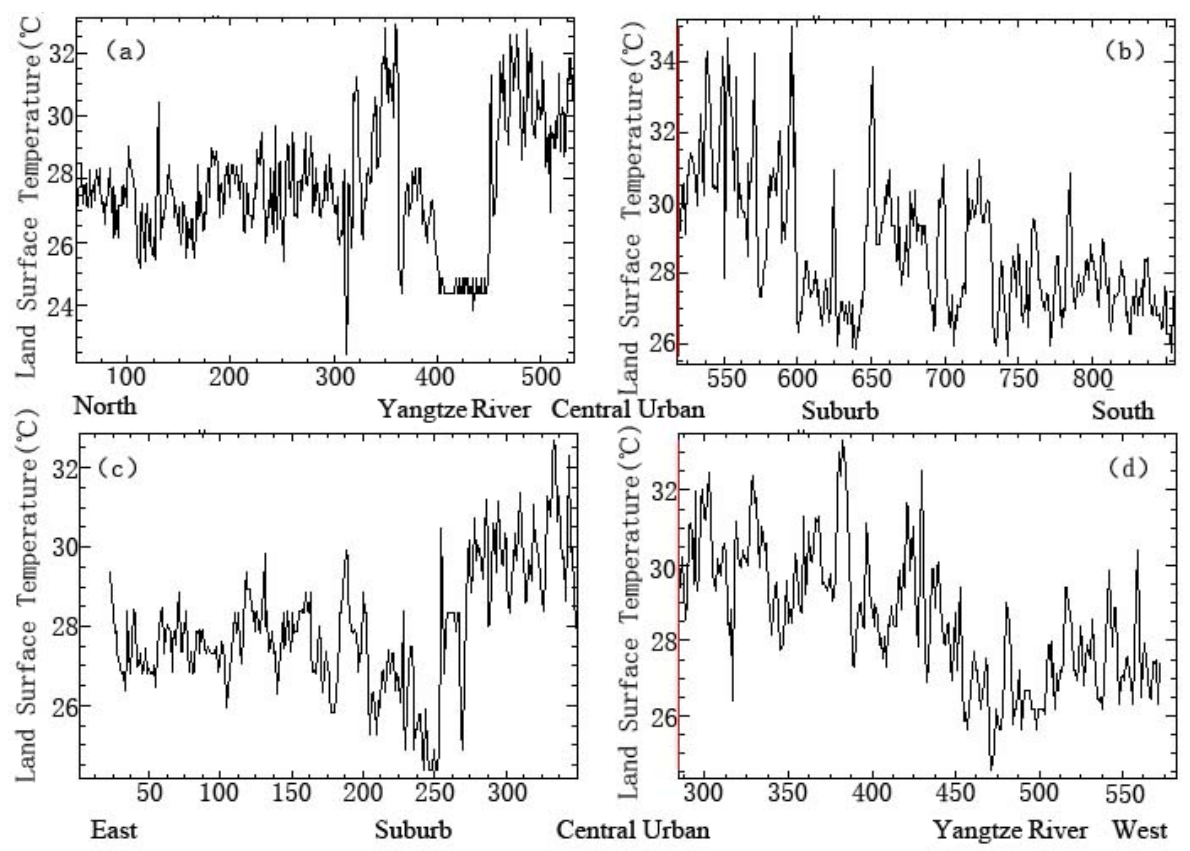

Figure 3. Spatial sectional view of LST in Nanjing on October 3,2009. From north to Central direction (a). From central to south direction (b). From east to central direction (c). From central to west direction $(d)$

The junction of the urban and rural areas has a low temperature because of high vegetation cover. The section of the profile running from east to central urban (Fig. 3c) and the corresponding place of low temperature is the junction of urban and rural areas. The section of the profile running from central urban to east (Fig. 3d) has a low 
temperature of about $26^{\circ} \mathrm{C}$. As a result, the temperature in central urban is higher by $8-6^{\circ} \mathrm{C}$ than that in Yangtze River and urban-rural junction with high vegetation cover.

\section{Characteristics of the temporal dimension of LST}

LST time series data from April 17, 2000 to October 14, 2013 is selected in the central city (Fig. 4a), the suburbs (Fig. 4b), the outer suburbs (Fig. 4c), and the outer suburbs near a lake (Fig. $4 d$ ) of Nanjing City (Fig. 4e). The high LST is $44^{\circ} \mathrm{C}$ in central city, $40^{\circ} \mathrm{C}$ in suburbs, $36^{\circ} \mathrm{C}$ in outer suburbs, and $33^{\circ} \mathrm{C}$ in outer suburbs near water. During the fourteen years of the presented time series data, urban development has expanded to the suburbs and impacted its LST. The land surface of the outer suburbs is less disturbed by humans and the LST is $5^{\circ} \mathrm{C}$ lower than that in central urban. The LST in the outer suburbs near the lake is lower than that in the outer suburbs, mainly because of the influence of the water surface.
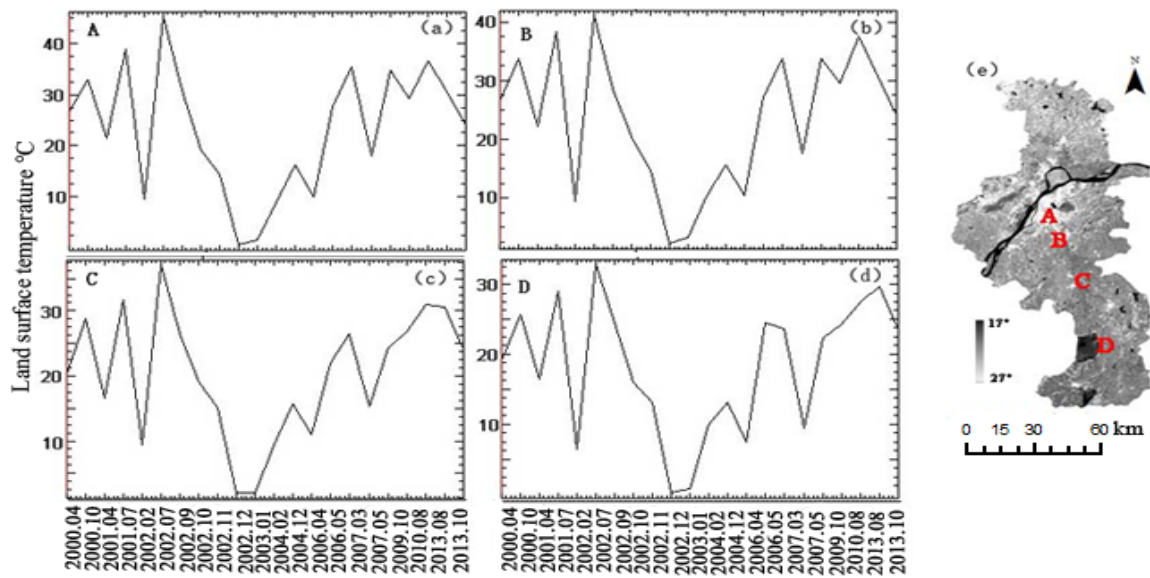

Figure 4. Time series of LST in Nanjing from Year 2000-2013. Time series curve in central urban (Fig.4a). Time series curve in suburbs (Fig.4b).Time series curve in outer suburbs

(Fig.4c). Time series curve in outer suburbs near lake (Fig.4d). Sample position map (Fig.4e)

\section{Characteristics of the fractal dimension of LST}

From 2000 to 2010, the LST of the central city in spring, summer, and autumn was $1-5^{\circ} \mathrm{C}$ higher than that of the suburbs (Jiangning, Qixia, and Pukou districts) and outer suburbs (Liuhe, Lishui, and Gaochun districts), for example, on July 12, 2002 and May 7, 2007 (Table 2).

Table 2. Zoning LST in Central urban, suburbs (Jiangning District, Qixia District, and Pukou District) and outer suburbs (Liuhe District, Lishui District, and Gaochun District) from 2000 to 2010. (Units: ${ }^{\circ} \mathrm{C}$ )

\begin{tabular}{c|c|c|c|c|c|c|c}
\hline & \multicolumn{9}{|c}{ District } \\
\hline Date & Central & Jiangning & Qixia & Pukou & Liuhe & Lishui & Gaochun \\
\hline $2000 / 04 / 17$ & 25.38 & 23.41 & 24.12 & 23.96 & 24.48 & 22.96 & 22.37 \\
$2000 / 10 / 10$ & 32.63 & 30.74 & 31.02 & 31.77 & 31.02 & 31.74 & 31.73 \\
$2001 / 04 / 04$ & 22.00 & 20.00 & 20.28 & 20.29 & 19.98 & 18.80 & 16.71 \\
$2001 / 07 / 17$ & 35.43 & 31.67 & 33.34 & 32.04 & 31.35 & 31.58 & 29.60 \\
$2002 / 02 / 10$ & 11.16 & 10.60 & 11.12 & 11.00 & 10.77 & 10.61 & 10.32 \\
$2002 / 07 / 12$ & 41.33 & 36.16 & 40.56 & 36.15 & 35.53 & 37.60 & 35.98 \\
$2002 / 09 / 30$ & 29.62 & 28.00 & 27.75 & 29.55 & 28.34 & 27.84 & 26.34 \\
\hline
\end{tabular}




\begin{tabular}{l|c|c|c|c|c|c|c}
\hline $2002 / 10 / 24$ & 20.90 & 20.01 & 19.68 & 20.65 & 20.03 & 20.09 & 20.80 \\
$2002 / 11 / 09$ & 15.98 & 15.97 & 15.88 & 16.43 & 16.43 & 15.87 & 16.18 \\
$2002 / 12 / 27$ & 2.11 & 2.57 & 2.30 & 2.60 & 1.92 & 2.61 & 2.00 \\
$2003 / 01 / 28$ & 3.18 & 3.20 & 3.20 & 3.40 & 2.03 & 2.78 & 2.00 \\
$2004 / 02 / 08$ & 11.74 & 12.60 & 12.34 & 12.65 & 11.66 & 12.18 & 12.10 \\
$2004 / 11 / 22$ & 16.53 & 16.71 & 16.12 & 16.26 & 16.33 & 17.11 & 16.60 \\
$2004 / 12 / 08$ & 11.85 & 11.71 & 11.98 & 11.97 & 11.40 & 11.82 & 11.40 \\
$2006 / 04 / 02$ & 27.31 & 26.00 & 24.74 & 25.24 & 24.80 & 23.96 & 23.08 \\
$2006 / 05 / 20$ & 32.30 & 30.65 & 30.27 & 30.68 & 31.67 & 30.00 & 30.62 \\
$2007 / 03 / 20$ & 18.14 & 16.71 & 17.72 & 17.06 & 16.60 & 16.02 & 15.02 \\
$2007 / 05 / 07$ & 33.74 & 29.65 & 30.30 & 29.87 & 30.43 & 28.51 & 26.00 \\
$2009 / 10 / 03$ & 28.56 & 27.37 & 28.14 & 27.41 & 27.21 & 27.20 & 27.16 \\
$2010 / 08 / 19$ & 34.22 & 30.52 & 32.68 & 30.60 & 29.75 & 29.63 & 29.54 \\
\hline
\end{tabular}

In winter, the LST is less than or close to that of the suburbs and the outer suburbs, such as on December 27, 2002 and February 8, 2004.

Comparing the LST of different years, the intensity of the heat island effect is decreased on May 20, 2006 and October 3, 2009. During the period 2007-2010, the LST difference between central urban and outer suburbs is small because urbanization has led to the expansion of urban space, thus the intensity of the heat island effect is relatively weakened.

\section{Relationship between LST and Land Cover}

In the GWR method, local $\mathrm{R}^{2}$ and standard residuals provide the criteria for judging the degree of fit to observational data. Local $\mathrm{R}^{2}$, ranges from 0 to 1 , and indicates the degree of local regression of the simulation for the observed values. Higher values indicate that the local regression model fits the results well, and lower values less-well. The coefficients represent the relationship between the two variables of LST and vegetation surface, and the related directions. The residual represents the difference between the observed and estimated values. The standard residual is zero.

Fig. 5 shows the correlation between LST and vegetation based on the GWR, in which the LST is the dependent variable and the vegetation abundance is the argument. High local $\mathrm{R}^{2}$ represents a strong correlation, and mainly occurs in the central area of Nanjing and the suburbs (Fig. 5a).
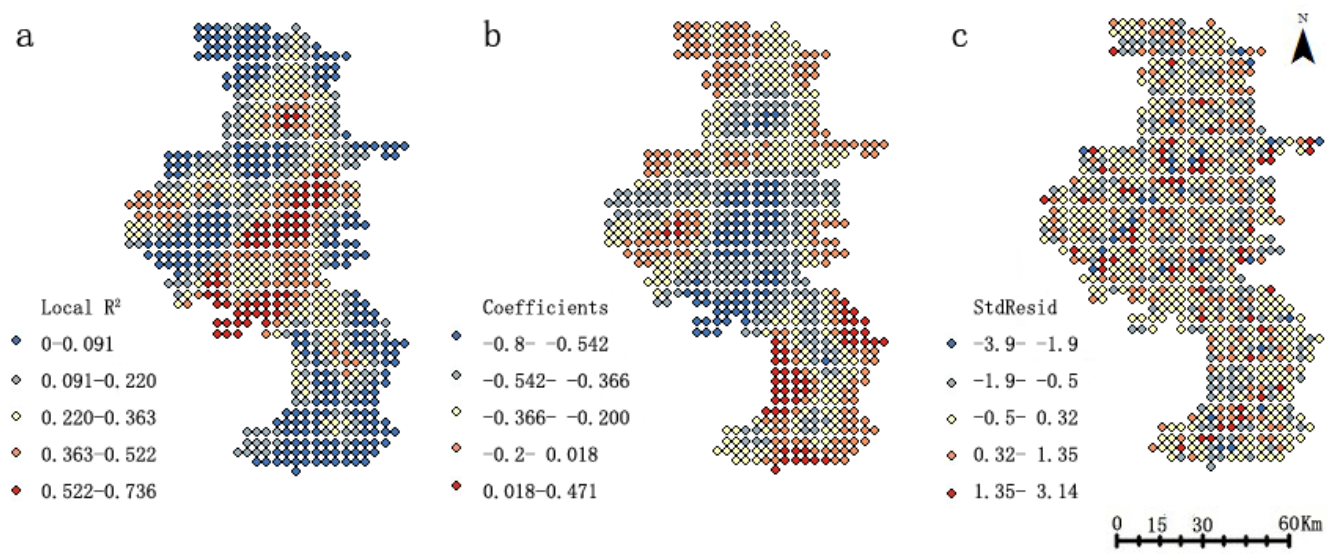

Figure 5. Correlation between LST and vegetation based on geographically weighted regression model in October 2009 in Nanjing City. Fig.5a is Local R2. Fig.5b is Coefficients. Fig.5c is StdResid 
Lower local $\mathrm{R}^{2}$ represents a relatively weak geographic linear correlation, and mainly occurs in the south and north of Nanjing. Vegetation in the Central district of Nanjing showed a stronger negative correlation with LST and the coefficient ranged from -0.8 to -0.542 (Fig. 5b). Vegetation abundance in the outer suburbs displayed a weak negative correlation with the LST. The distance from the central district has a significant impact on the relationship between vegetation and LST. Positive residuals represent a high predictive value and negative residuals a low value (Fig. 5c). On the whole, the standard residuals are distributed in an apparently random pattern, and all residual values are lower than four, thus the overall model fit well.

Figure 6 shows the correlation between LST and impervious surface abundance based on GWR. The high $\mathrm{R}^{2}$ is mainly distributed in the central district and southern suburbs of Nanjing where the LST and impervious surface have a strong correlation (Fig. 6a). The coefficient of LST and impervious surfaces are all positive, showing a significant positive correlation (Fig. $6 b$ ). The coefficients in the urban center range from 0.803 to 1.045 . The impervious surface has a significant impact on land surface warming. Absolute values of the majority of standard residuals are lower than 1 , indicating that the model fit very well (Fig. 6c).
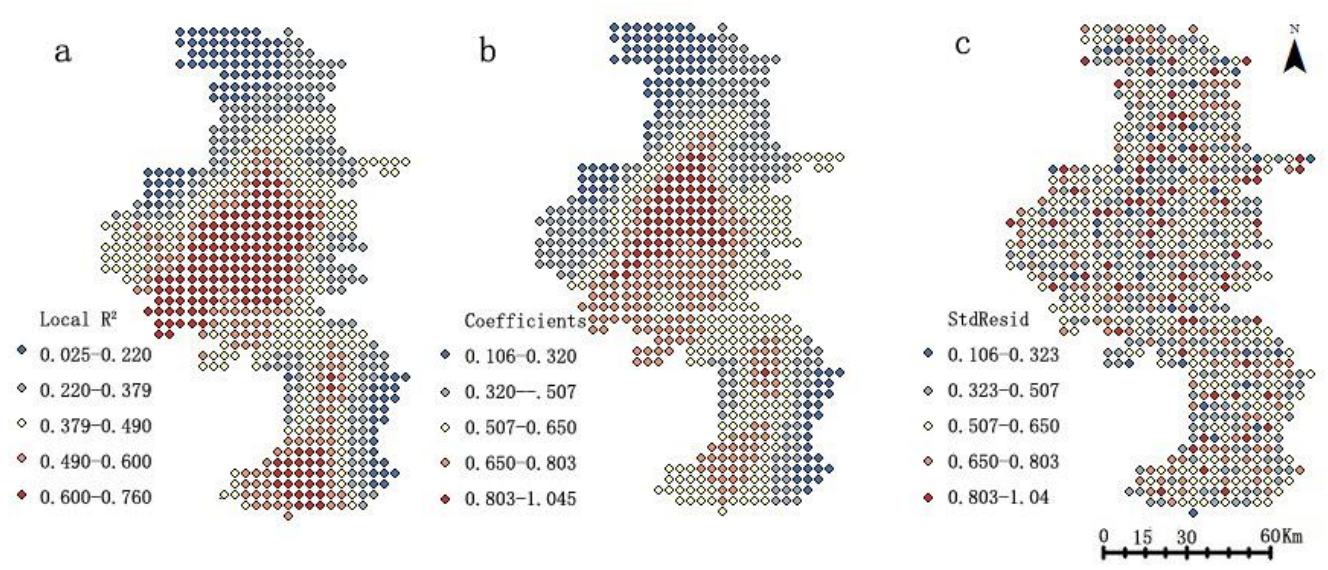

Figure 6. Correlation between LST and impervious surface based on geographically weighted regression model in October 2009 in Nanjing City. Fig.6a is Local R2. Fig.6b is Coefficients. Fig.6c is StdResid

Comparing Fig. $5 b$ to Fig. $6 b$, the coefficients in the central district for vegetation and impervious surfaces range from -0.800 to -0.542 and from 0.803 to 1.045 , respectively. The promoting role of impervious surface is much higher than the cooling effects of vegetation on LST.

Figure 7 shows the correlation between LST and water from GWR, in which the LST is the dependent variable and water abundance is the argument. The high $\mathrm{R}^{2}$ is mainly distributed in the middle and north of Nanjing in the proximity of the Yangtze River and Gucheng Lake (Fig. 7a). The high local $\mathrm{R}^{2}$ reaches 0.538 indicating that there is a good fit between LST and water. The coefficients in the south and middle of Nanjing are negative valued which signifies a negative correlation between LST and water (Fig. 7b). Along the Yangtze River, the coefficients are low (-1.64 to -1.07), thus, the Yangtze River forms a band which impedes heat transfer, and further slows down 
the urban heat island effect. The absolute value of the standard residuals is less than four signifying that the model fit well (Fig. $7 c$ ).

Comparing Fig. $5 b$ to Fig. $7 b$, the low coefficients for vegetation and water surface fitting with LST are -0.8 and -1.64 , respectively, thus the water surface has a more obvious effect on adjusting the LST than the vegetation.

\section{Relationship between LST and Landscape Indices}

Landscape indices can describe the detailed pattern of the land surface. Landscape diversity indices include patch richness density and Shannon's diversity index. Landscape fragmentation indices include number of patches, patch density, division and splitting indices. These indicators are selected to reflect different aspects of landscape features and to verify the accuracy of the indicators (Table 3).

The Shannon's diversity index of the central city is 1.1691 , and is the smallest of all districts. Diversity indices of the suburbs (Qixia, Pukou, and Jiangning districts) are 1.4072, 1.4287, and 1.4270. Diversity indices of the outer suburbs (Lishui, Liuhe, and Gaochun districts) are 1.4848, 1.4288, and 1.5037.

The division index of the central city is 0.7664 , and is the smallest of all districts. Division indices of the suburbs (Qixia, Pukou, and Jiangning districts) are 0.8819, 0.9737, and 0.9777. Division indices of the outer suburbs (Lishui, Liuhe, and Gaochun districts) are $0.9853,0.9723$, and 0.9677 .
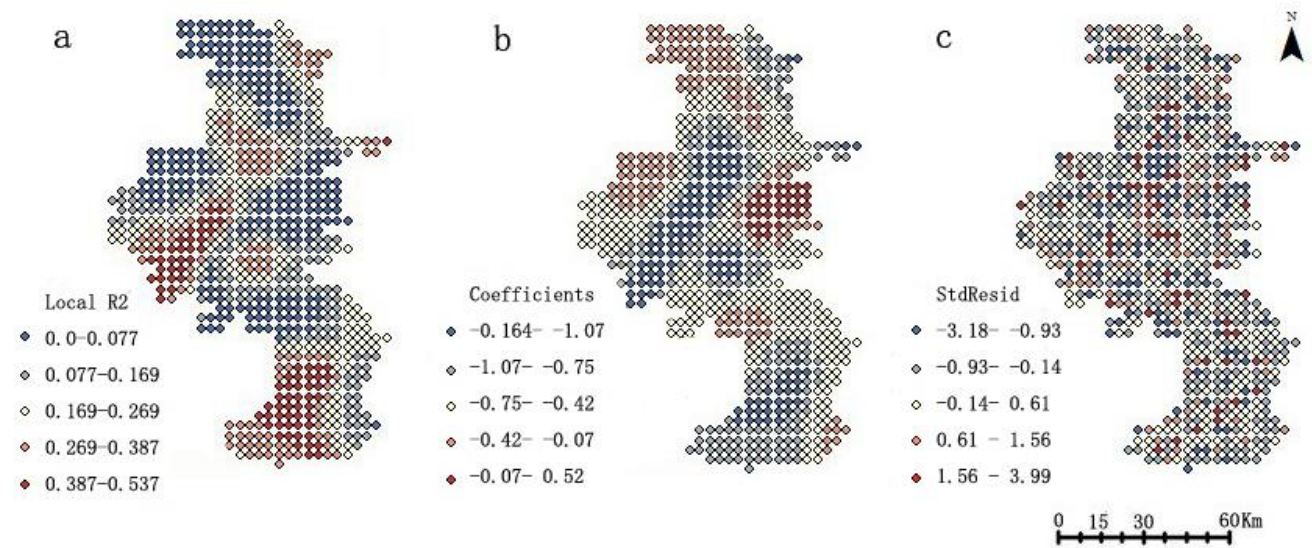

Figure 7. Correlation between LST and water surface based on geographically weighted regression model in October 2009 in Nanjing City. Fig.7a is Local R2. Fig.7b is Coefficients. Fig.7c is StdResid

Table 3. Landscape index in Nanjing zones on May 20, 2006

\begin{tabular}{c|c|c|c|c|c|c}
\hline \multirow{2}{*}{ District } & \multicolumn{6}{|c}{ Landscape indices } \\
\cline { 2 - 7 } & $\begin{array}{c}\text { Number of } \\
\text { patches }\end{array}$ & Patch density & Division index & $\begin{array}{c}\text { Splitting } \\
\text { index }\end{array}$ & $\begin{array}{c}\text { Patch } \\
\text { richness } \\
\text { density }\end{array}$ & $\begin{array}{c}\text { Shannon's } \\
\text { diversity index }\end{array}$ \\
\hline Lishui & 99019 & 92.93 & 0.9853 & 68.08 & 0.0047 & 1.4848 \\
Liuhe & 132821 & 90.08 & 0.9723 & 36.15 & 0.0034 & 1.4288 \\
Pukou & 80495 & 88.72 & 0.9737 & 37.96 & 0.0055 & 1.4287 \\
Qixia & 20283 & 51.79 & 0.8819 & 8.46 & 0.0128 & 1.4072 \\
Central & 18084 & 50.19 & 0.7664 & 4.28 & 0.0139 & 1.1691 \\
Jiangning & 147583 & 91.91 & 0.9777 & 44.84 & 0.0031 & 1.4270 \\
Gaochun & 69328 & 86.29 & 0.9677 & 30.95 & 0.0062 & 1.5037 \\
\hline
\end{tabular}


The diversity index in the central city is lowest of all, and the LST and EVI display a significant negative correlation. Diversity indices in the suburbs are in the middle value of all. The LST and EVI have a weak negative correlation (Fig. 8). Diversity indices in the outer suburbs are the largest of all the sites, and the LST and EVI show substantially no linear correlation.

If the landscape diversity indices are smaller, the LST has a more obvious negative correlation with the vegetation index. Conversely, if the landscape diversity indices are greater, the LST response to the vegetation index is weaker.

Similarly, if landscape fragmentation indices are smaller, the LST has a more obvious negative correlation with the vegetation index. Conversely, if landscape fragmentation indices are greater, the LST response to the vegetation index is weaker.
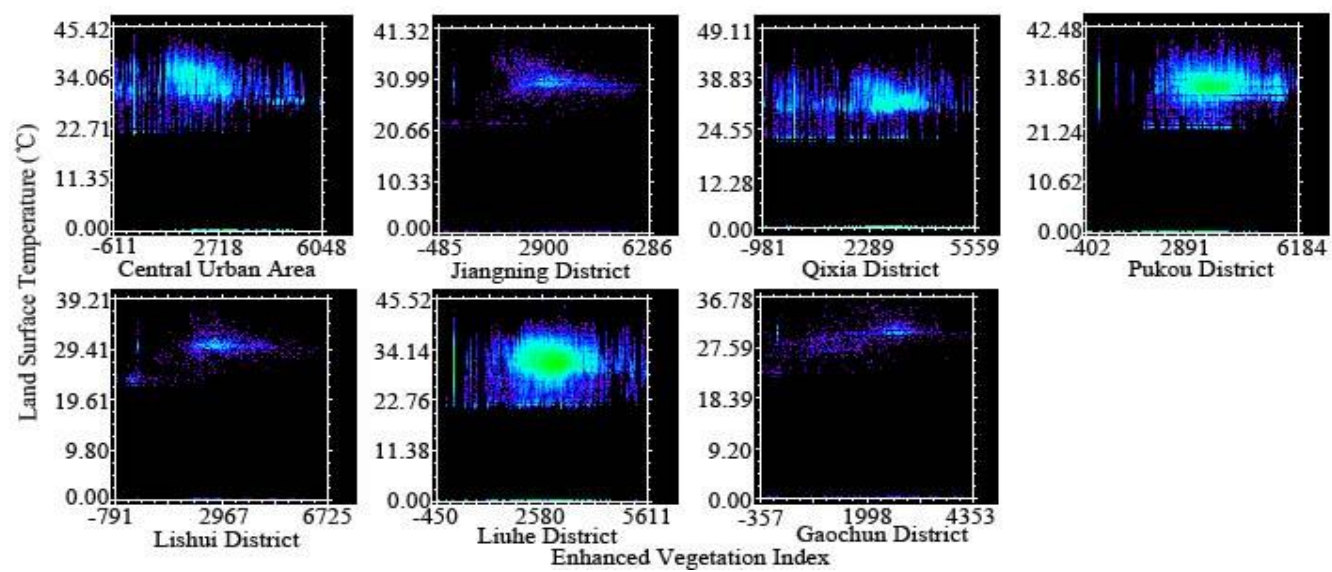

Figure 8. The relation of LST and enhanced vegetation index (EVI) under different landscape indexes in Nanjing zones. $X$ axis is enhance vegetation index and $Y$ axis is LST

\section{Conclusions}

In the spatial dimension, the high temperature is in the central city, and the low temperature is in the suburbs and the Yangtze River, and there was a $6-8^{\circ} \mathrm{C}$ temperature difference on October 3, 2009. In the temporal dimensional, the maximum LSTs in the central city, suburbs, outer suburbs and outer suburbs near water are 44, 40, 36, and $33^{\circ} \mathrm{C}$, respectively. In the fractal dimension, the LST of the central city in spring, summer, and autumn is $1-5^{\circ} \mathrm{C}$ higher than that of the suburbs. In winter, the LST of the central city is less than or close to that of the suburbs.

In the quantitative relation between the LST and urban reflectance, vegetation in the Central District of Nanjing showed a stronger negative correlation with LST and the coefficient is -0.8. Impervious surface in the central district of Nanjing displayed an extinctive positive correlation with the LST and the highest coefficient is 1.045. The promoting role of impervious surface is considerably higher than the cooling effects of vegetation on LST. The water surface of Gucheng Lake had a negative correlation with LST and a low coefficient of -1.64 . The water surface has a more obvious effect on adjusting the LST.

The landscape diversity indices and fragmentation indices have a negative relationship with both the LST and vegetation index. If the landscape diversity indices are smaller, the LST has a more noticeable negative correlation with the vegetation 
index. Similarly, if the landscape fragmentation indices are smaller, LST has a more obvious negative correlation with the vegetation index.

\section{Discussions}

In this research, the GWR model is utilized to explore the scale-dependent and spatial non-stationary relationships between LST and urban reflectance. In the GWR model, the strength of the regression relationships increased significantly, with a mean of $59 \%$ of the changes in LST values explained by the predictors, compared with only $43 \%$ using the ordinary least squares model ( $\mathrm{Li}$ et al., 2010). The most important problem for the GWR method is to set the local regression parameters and select a suitable bandwidth, which involves the problem of spatial autocorrelation. Here the local regression parameters are set to be adaptive and not consider the spatial autocorrelation factor. However, spatial autocorrelation is a key issue for future research. The land cover and land surface temperature have the same trend with the published paper (Liu et al., 2016; Wang et al., 2018).

Scaling is another important factor effecting the relationship between landscape patterns and LST. Thirty meters was found to be the optimal resolution in the study of the relationship between urban relectance and LST classes. Ninety meters was found to be the optimal spatial resolution for assessing the landscape-level relationship between land cover and LST patterns (Liu and Weng, 2009). Here the Landsat dataset of 30 meters resolution was selected to derive the LST.

The impact of urbanization on the urban heat island can be mitigated not only by balancing land use patterns, but also by optimizing the spatial landscape (Zhou et al., 2011). Landscape patterns can determine the land function. The same amount of vegetation cover in different landscape patterns will play a different role in slowing LST. The composition metric alone explains about 56\% of the landscape mean LST. Whereas, adding a configuration explains approximately another 6-12\% (Chen et al., 2014). Here we study the correlation between LST and vegetation index under different landscape index conditions; a focus of research on the quantitative relation between LST and urban landscape pattern.

Acknowledgements. The research was supported by the National Natural Science Foundation of China (Key Program) (41730642), National Natural Science Foundation of China (NSFC) project (no. 41401094) and Shanghai Normal University project (307-AC0302-19-005416). We thank the anonymous reviewers for the numerous helpful comments and suggestions.

Competing interests. The authors declare no competing interests.

\section{REFERENCES}

[1] Alavipanah, S., Wegmann, M., Qureshi, S., Weng, Q. H., Koellner, T. (2015): The Role of Vegetation in Mitigating Urban Land Surface Temperatures: A Case Study of Munich, Germany during the Warm Season. - Sustainability 7(4): 4689-4706.

[2] Atitar, M., Sobrino, J. A. (2009): A split-window algorithm for estimating LST from Meteosat 9 data: Test and comparison with in situ data and MODIS LSTs. - IEEE Geoscience and Remote Sensing Letters 6(1): 122-126. 
[3] Berk, A., Bernstein, L., Robertson, D. C. (1987): MODTRAN: A moderate resolution model for LOWTRAN. - SPECTRAL SCIENCES INC BURLINGTON MA 9: 325.

[4] Buyantuyev, A., Wu, J. (2010): Urban heat islands and landscape heterogeneity: linking spatiotemporal variations in surface temperatures to land-cover and socioeconomic patterns. - Landscape ecology 25(1): 17-33.

[5] Chen, A., Yao, L., Sun, R. H., Chen, L. D. (2014): How many metrics are required to identify the effects of the landscape pattern on land surface temperature? - Ecological Indicators 45: 424-433.

[6] Clement, F., Orange, D., Williams, M., Mulley, C., Epprecht, M. (2009): Drivers of afforestation in Northern Vietnam: assessing local variations using geographically weighted regression. - Applied Geography 29(4): 561-576.

[7] Coll, C., Valor, E., Galve, J. M., Mira, M., Bisquert, M., García-Santos, V., Caselles, E., Caselles, V. (2012): Long-term accuracy assessment of land surface temperatures derived from the Advanced Along-Track Scanning Radiometer. - Remote Sensing of Environment 116: 211-225.

[8] Du, S. H., Xiong, Z. Q., Wang, Y. C., Guo, L. (2016): Quantifying the multilevel effects of landscape composition and configuration on land surface temperature. - Remote Sensing of Environment 178: 84-92.

[9] Fotheringham, A. S., Charlton, M. E., Brunsdon, C. (2001): Spatial variations in school performance: a local analysis using geographically weighted regression. - Geographical and Environmental Modelling 5(1): 43-66.

[10] Fu, P., Weng, Q. (2016a): Consistent land surface temperature data generation from irregularly spaced Landsat imagery. - Remote Sensing of Environment 184: 175-187.

[11] Fu, P., Weng, Q. (2016b): A time series analysis of urbanization induced land use and land cover change and its impact on land surface temperature with Landsat imagery. Remote Sensing of Environment 175: 205-214.

[12] Haashemi, S., Weng, Q. H., Darvishi, A., Alavipanah, S. K. (2016): Seasonal Variations of the Surface Urban Heat Island in a Semi-Arid City. - Remote Sensing 8(4): 352.

[13] Hulley, G. C., Hook, S. J. (2011): Generating consistent land surface temperature and emissivity products between ASTER and MODIS data for earth science research. - IEEE Transactions on Geoscience and Remote Sensing 49(4): 1304-1315.

[14] Jim, C. Y., Chen, S. S. (2003): Comprehensive greenspace planning based on landscape ecology principles in compact Nanjing city, China. - Landscape and Urban Planning 65(3): 95-116.

[15] Landsberg, H. E. (1981): The urban climate. International Geophysics Series. - Academic Press, New York 28: 275.

[16] Lee, T. W., Lee, J. Y., Wang, Z. H. (2012): Scaling of the urban heat island intensity using time-dependent energy balance. - Urban Climate 2: 16-24.

[17] Li, S., Zhao, Z. Q., Xie, M. M., Wang, Y. L. (2010): Investigating spatial non-stationary and scale-dependent relationships between urban surface temperature and environmental factors using geographically weighted regression. - Environmental Modelling \& Software 25(12): 1789-1800.

[18] Li, Y. Y., Zhang, H., Kainz, W. (2012): Monitoring patterns of urban heat islands of the fast-growing Shanghai metropolis, China: Using time-series of Landsat TM/ETM+ data. - International Journal of Applied Earth Observation and Geoinformation 19: 127-138.

[19] Li, B., Chen, D., Wu, S., Zhou, S., Wang, T., Chen, H. (2016): Spatio-temporal assessment of urbanization impacts on ecosystem services: Case study of Nanjing City, China. - Ecological Indicators 71: 416-427.

[20] Liu, H., Weng, Q. (2009): Scaling effect on the relationship between landscape pattern and land surface temperature. - Photogrammetric Engineering \& Remote Sensing 75(3): 291-304. 
[21] Liu, G., Zhang, Q., Li, G., Doronzo, D. M. (2016): Response of land cover types to land surface temperature derived from Landsat-5 TM in Nanjing Metropolitan Region, China. - Environmental Earth Sciences 75(20): 1386.

[22] Mao, K. B., Shi, J. C., Tang, H. J., Li, Z. L., Wang, X. F., Chen, K. S. (2008): A neural network technique for separating land surface emissivity and temperature from ASTER imagery. - IEEE Transactions on Geoscience and Remote Sensing 46(1): 200-208.

[23] Qin, Z., Dall'Olmo, G., Karnieli, A., Berliner, P. (2001a): Derivation of split window algorithm and its sensitivity analysis for retrieving land surface temperature. - Journal of Geophysical Research: Atmospheres 106(19): 22655-22670.

[24] Qin, Z., Karnieli, A., Berliner, P. (2001b): A mono-window algorithm for retrieving land surface temperature from Landsat TM data and its application to the Israel-Egypt border region. - International Journal of Remote Sensing 22(18): 3719-3746.

[25] Quattrochi, D. A., Luvall, J. C., Rickman, D. L., Estes Jr, M. G., Laymon, C. A., Howell, B. F. (2000): A decision support information system for urban landscape management using thermal infrared data: Decision support systems. - Photogrammetric Engineering and Remote Sensing 66(10): 1195-1207.

[26] Rajasekar, U., Weng, Q. (2009): Urban heat island monitoring and analysis using a nonparametric model: A case study of Indianapolis. - ISPRS Journal of Photogrammetry and Remote Sensing 64(1): 86-96.

[27] Rao, P. K., Smith, W. L., Koffler, R. (1972): Global sea-surface temperature distribution determined from an environmental satellite. - Monthly Weather Review 100(1): 10-14.

[28] Roth, M., Oke, T. R., Emery, W. J. (1989): Satellite-derived urban heat islands from three coastal cities and the utilization of such data in urban climatology. - International Journal of Remote Sensing 10(11): 1699-1720.

[29] Rozenstein, O., Qin, Z. H., Derimian, Y., Karnieli, A. (2014): Derivation of land surface temperature for Landsat-8 TIRS using a split window algorithm. - Sensors 14(14): 57685780.

[30] Schwarz, N., Schlink, U., Franck, U., Großmann, K. (2012): Relationship of land surface and air temperatures and its implications for quantifying urban heat island indicators - an application for the city of Leipzig (Germany). - Ecological Indicators 18: 693-704.

[31] Small, C. (2001): Estimation of urban vegetation abundance by spectral mixture analysis. - International Journal of Remote Sensing 22(7): 1305-1334.

[32] Small, C. (2004): The Landsat ETM+ spectral mixing space. - Remote Sensing of Environment 93(1-2): 1-17.

[33] Small, C. (2005): A global analysis of urban reflectance. - International Journal of Remote Sensing 26(4): 661-681.

[34] Small, C., Lu, J. W. (2006): Estimation and vicarious validation of urban vegetation abundance by spectral mixture analysis. - Remote Sensing of Environment 100(4): 441456.

[35] Small, C., Milesi, C. (2013): Multi-scale standardized spectral mixture models. - Remote Sensing of Environment 136: 442-454.

[36] Sobrino, J. A., Jiménez-Muñoz, J. C., Paolini, L. (2004): Land surface temperature retrieval from LANDSAT TM 5. - Remote Sensing of Environment 90(4): 434-440.

[37] Sobrino, J. A., Jiménez-Muñoz, J. C. (2005): Land surface temperature retrieval from thermal infrared data: An assessment in the context of the Surface Processes and Ecosystem Changes through Response Analysis (SPECTRA) mission. - Journal of Geophysical Research: Atmospheres 110(16): 19.

[38] Sobrino, J. A., Jimenez-Munoz, J. C., Soria, G., Romaguera, M., Guanter, L., Moreno, J., Plaza, A., Martinez, P. (2008): Land surface emissivity retrieval from different VNIR and TIR sensors. - IEEE Transactions on Geoscience and Remote Sensing 46(2): 316-327.

[39] Streutker, D. R. (2002): A remote sensing study of the urban heat island of Houston, Texas. - International Journal of Remote Sensing 23(13): 2595-2608. 
[40] Su, Y. F., Foody, G. M., Cheng, K. S. (2012): Spatial non-stationarity in the relationships between land cover and surface temperature in an urban heat island and its impacts on thermally sensitive populations. - Landscape and Urban Planning 107(2): 172-180.

[41] Wang, N., Li, Z. L., Tang, B. H., Zeng, F. N., Li, C. R. (2013): Retrieval of atmospheric and land surface parameters from satellite-based thermal infrared hyperspectral data using a neural network technique. - International Journal of Remote Sensing 34(9-10): 34853502 .

[42] Wang, S., Ma, Q., Ding, H., Liang, H. (2018): Detection of urban expansion and land surface temperature change using multi-temporal landsat images. - Resources, Conservation and Recycling 128: 526-534.

[43] Weng, Q. (2001): A remote sensing? GIS evaluation of urban expansion and its impact on surface temperature in the Zhujiang Delta, China. - International Journal of Remote Sensing 22(10): 1999-2014.

[44] Weng, Q., Lu, D. S., Schubring, J. (2004): Estimation of land surface temperaturevegetation abundance relationship for urban heat island studies. - Remote Sensing of Environment 89(4): 467-483.

[45] Zhang, Y., Chen, Y. Y., Qing, D., Jiang, P. (2012): Study on urban heat island effect based on Normalized Difference Vegetated Index: a case study of Wuhan City. Procedia Environmental Sciences 13: 574-581.

[46] Zhou, X., Wang, Y. C. (2011): Dynamics of Land Surface Temperature in Response to Land Use/Cover Change. - Geographical Research 49(1): 23-36.

[47] Zhou, W. Q., Huang, G. L., Cadenasso, M. (2011): Does spatial configuration matter? Understanding the effects of land cover pattern on land surface temperature in urban landscapes. - Landscape and Urban Planning 102(1): 54-63. 